$\checkmark$ and of US physics in general are well narrated. The newcomers made mistakes and missed opportunities, but European physicists - including such giants as Rutherford, James Chadwick and Pierre and Marie Curie - maintained a dialogue, and respected them. Lawrence and his team stayed engaged, increasingly willing to admit to errors as their confidence grew, and generous with their know-how in helping to start other accelerator programmes as the 'Cyclotron Republic' grew.

Compelling characters abound. There is the mysterious and influential Alfred Loomis, a patron of science who achieves the feat of "being a public figure without letting the public in on it". Later, there is Lewis Strauss (pronounced 'Straws'), Washington DC insider, chair of the Atomic Energy Commission and die-hard opponent of a nuclear-test-ban treaty. Lawrence seems to have easily formed bonds with exceptional people, but these sometimes shattered, as with Manhattan Project leader J. Robert Oppenheimer, causing damage and dismay.

Lawrence transformed strikingly from a man who insisted that politics had no place in the lab to one who played high-stakes political games around the credibility of scientific advice on nuclear-weapon development - and fired outstanding scientists because they refused to sign an oath of loyalty. The Rad Lab drew talent, but much of it leaked or was driven away as Berkeley became identified with the anti-communist McCarthyism - under which people were branded un-American and unemployable — that abounded in the military-industrial complex that it had helped to create.

The final chapter rushes through the for-

"The Rad Lab mation of CERN drew talent, but much of it leaked or was driven away as Berkeley became identified with McCarthyism." in Geneva, Switzerland, and the failure of its US competitor, the Superconducting Super Collider, which was cancelled in the 1990s. It is a compliment to Hiltzik that, having initially worried about the book's size, I wanted more - in particular, on how CERN consciously distanced itself from the military aspect of the complex, and how the teamwork that Lawrence developed applies, or fails to, in collaborations of thousands rather than dozens. Lawrence had left the scene by then, but his influence still pervades academia, industry and politics.

Jon Butterworth is professor of physics at University College London and writes for The Guardian at go.nature.com/qhea9i. He is the author of Smashing Physics. e-mail:j.butterworth@ucl.ac.uk

\title{
The impulse of beauty
}

\section{Joseph Silk revels in Frank Wilczek's treatise on how symmetry and harmony drive the progress of science.}

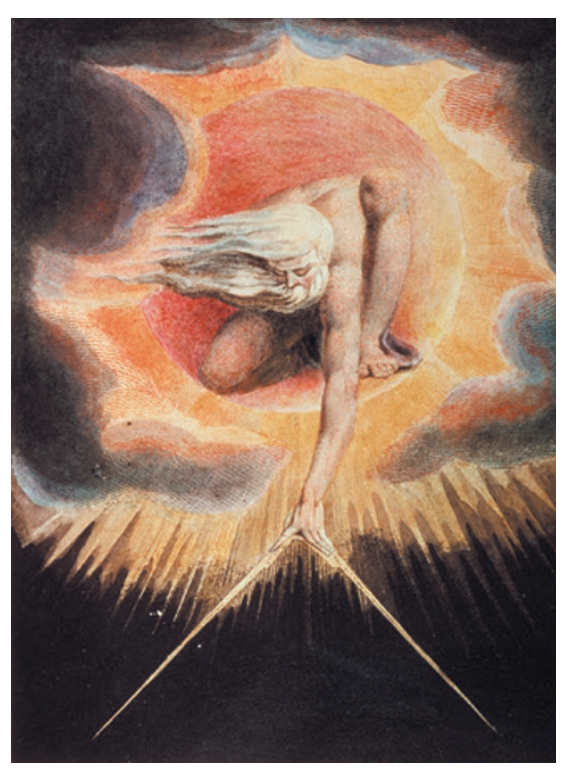

Through the mythological figure of Urizen, William Blake probed the nature of reductionism.

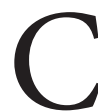

an beautiful ideas drive science? In A Beautiful Question, physicist and Nobel laureate Frank Wilczek makes a potent case that they can, hinging on qualities that have served as pathfinders to empirical truth in the physical world. The greatest scientists, from Galileo to Albert Einstein, saw in physics almost infinite beauty, including symmetry, harmony and truth. Today, we fervently hope for a genius with a beautyinspired Theory of Everything - or at least for the Large Hadron Collider at CERN in Geneva, Switzerland, to discover truth in supersymmetry.

A Beautiful Question is both a brilliant exploration of largely uncharted territories and a refreshingly idiosyncratic guide to developments in particle physics. Vast and eclectic, it covers everything from atomism to the Higgs boson, musical harmony to anamorphic art, dark matter to the origins of the Universe. Wilczek lays out a vision of truth and beauty inspired by great modern physicists and classical philosophers such as Pythagoras and Plato. Lavish illustrations exemplifying beauty in art and science, from William Blake's Ancient of Days to fractal images, are interwoven with quotations from luminaries in the arts and sciences, from Molière to John Archibald Wheeler.

Wilczek begins with the beauty-inspired seeds sown by the ancient Greeks, including the fundamentals of geometry, music and chemistry. The music of the spheres, which Pythagoras described as the hum from celestial bodies whose periodicities echoed a harmony that he alone heard, inspired him and his followers to develop harmonies between beauty, music, mathematics and science. Numbers governed all, from octaves to right-angled triangles. Through perspective, geometry revolutionized classical, then Renaissance, art; through the curvature of space, it revolutionized understanding of gravity. And Wilczek argues that colour, the epicentre of beauty, unites art with biology, chemistry and physics.

The search for symmetry generated enormous rewards in science, a gift that has kept on giving. In the nineteenth century, Michael Faraday gave an elegant display of empirical physics by mapping out the patterns of magnetic lines of force. He went on to show that moving magnetic fields generate electric fields, motivating mathematical physicist James Clerk Maxwell to develop his equations for electromagnetism. These epitomized a fundamental symmetry, allowing a magnetic field in motion to generate an electric field, and vice versa. The fields propagate through space, producing waves of light in all colours of the rainbow. Maxwell's equations also predicted that electromagnetic waves would propagate at frequencies beyond perception by the human eye. Inspired, Heinrich Hertz discovered radio waves. Beauty had succeeded far beyond any intent of Faraday's.

Wielding the sword of beauty to refine scientific thought has a remarkable heritage. Einstein put beauty first in conceptualizing the general theory of relativity. In the dreary postwar climate of 1919 , worldwide headlines greeted the successful verification of one of his key predictions - the bending of light by gravity. Another triumph is the standard model of particle physics, whose symmetries led to prediction of the Higgs boson.

Wilczek argues that the quantum core of modern physics, the zoo of elementary

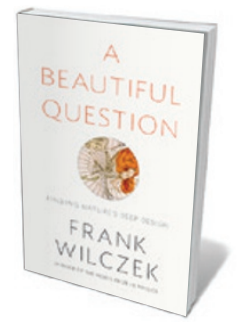

A Beautiful Question: Finding Nature"s Deep Design FRANK WILCZEK Allen Lane: 2015. 
particles, stems from beautiful thoughts framed by appeals to symmetry. The Eightfold Way, named by physicist Murray Gell-Mann after the Noble Eightfold Path of Buddhism, organizes elementary particles into octets; the Higgs, discovered in 2012, is the final missing link in the standard model.

Now the search is on for a unifying principle to take us back to simplicity. Supersymmetry, the most beautiful idea of all, unites two fundamental types of particles, fermions and bosons, distinguished by their spins. It postulates massive 'superpartners' for each particle, the lightest of which is a stable candidate for dark matter. Some see a lack of elegance in a theory that has some 120 adjustable degrees of freedom. The situation is, however, being redeemed in part through the enormous efforts of experimental particle physicists to measure many of these numbers. Only one real issue remains: at what energies must one smash particles together to seek supersymmetry's elusive signature? Wilczek optimistically predicts that we will discover this holy grail of physics in five years.

Occasionally the search for beauty has led us astray. Science was set back for centuries by the epicycles with which Greek astronomer Ptolemy described planetary motions. Modern data debunked Fred Hoyle's steady-state theory of the Universe. And even particle physics, with its grand hopes of unification, offers no insight into serious cosmological problems such as why dark matter is more than five times as abundant as ordinary matter. Most recently there has been string theory, the compellingly beautiful union of mathematical simplicity with quantum theory, particle physics and gravity. Its advocates have provoked a controversy: can a theory be so beautiful that we award it scientific accolades for its synthetic capacity without an empirical test, or must we dump it on the scrap heap of history for its lack of grounding truth?

Persistent voices insist that a theory of physics must lead to experimental verification. Wilczek is emphatic about this, as was Isaac Newton, who would like us to see empiricism as the search for truth. If truth and beauty are inseparable, that circle is closed. That is where supersymmetry will rise or fall. I hope for the latter, although I am reconciled to waiting for a new generation of unprecedentedly powerful particle colliders to reach the frontiers of our unifying theory.

Joseph Silk is at the Institut d'Astrophysique de Paris, the Beecroft Institute for Particle Astrophysics and Cosmology in Oxford, UK, and the Johns Hopkins University in Baltimore, Maryland. e-mail:joseph.silk@physics.ox.ac.uk

\section{Books in brief}

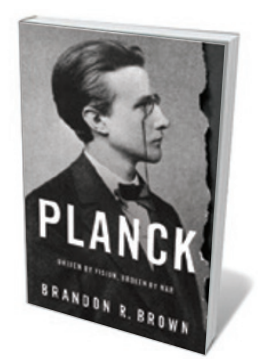

Planck: Driven by Vision, Broken by War

Brandon R. Brown OXFORD UNIVERSITY PRESS (2015)

The life of Max Planck, 'father of quantum theory', smacks of enigma: his personal papers were mostly destroyed in the Second World War. Physicist Brandon Brown has mined what survived for this illuminating biography. The main thread is the endgame of the Second World War, when the elderly Planck endured tribulations such as his son Erwin's trial and execution for treason against the Reich. Through this Brown interweaves a gripping backstory, ranging from Planck's landmark theoretical description of blackbody radiation to his loyal advocacy for fellow physicist Lise Meitner.

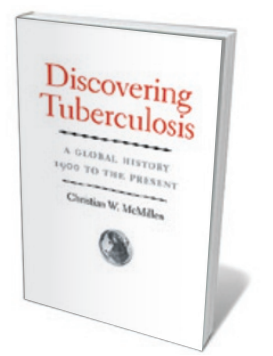

Discovering Tuberculosis: A Global History, 1900 to the Present Christian W. McMillen YALE UNIVERSITY PRESS (2015)

Polio incidence is down by $99 \%$ since 1988 , but tuberculosis (TB) remains a scourge; it kills 2 million people a year, most with HIV/AIDS. In his chronicle of TB's trajectory from the start of the twentieth century, historian Christian McMillen probes our failure to control this "resilient, powerful, protean bacterial infection" and its drug-resistant strains. Tracing the swathe TB has cut through Africa, India and Native American areas, McMillen identifies the catalogue of errors keeping it in circulation - such as the closure of the UK Medical Research Council's TB units in 1986, just as Africa's struggle with HIV began.

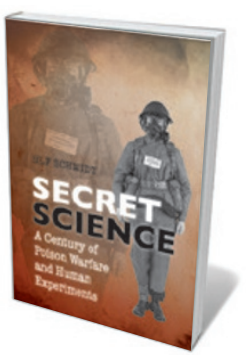

Secret Science: A Century of Poison Warfare and Human Experiments Ulf Schmidt OXFORD UNIVERSITY PRESS (2015)

This monumental history of twentieth-century military medical ethics is a meticulous record of ambiguity. Historian Ulf Schmidt shows how Germany's use of chemical weapons such as mustard gas in the First World War spurred Britain, Canada and the United States to begin secret toxic-agent trials that purported, in some cases, to be benign medical testing. At the UK Porton Down research centre alone, Schmidt reveals, 21,752 soldiers took part in tests between 1939 and 1989 - an experience that was frequently unpleasant, occasionally harmful and in a few cases fatal.

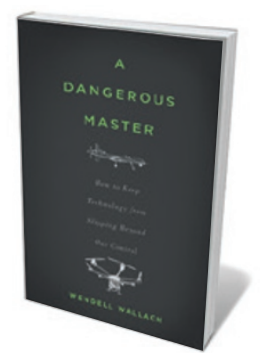

A Dangerous Master: How to Keep Technology from Slipping Beyond Our Control

Wendell Wallach BASIC (2015)

Hordes of technologies emerge in lockstep with warnings of their risks. Ethicist Wendell Wallach sorts the hysteria from the hazards in this magisterial study. He looks in turn at disruption, complex systems, problematic trade-offs, the "transhumanism" movement - and new forms of governance to guide us through the innovatory onrush. It is conscious engagement, Wallach argues, that will allow us to resist the truly dangerous developments that threaten to "woo us to sleepwalk into the technological wonderland".

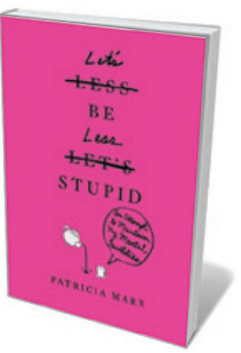

Let's Be Less Stupid: An Attempt to Maintain My Mental Faculties Patricia Marx TWELVE (2015)

Struggling with brain fog? This "sub-primer" on the neuroscience of intelligence and memory by New Yorker staff writer and master humorist Patricia Marx delivers salutary cognitive jolts amid the general hilarity. Through a "higgledy-piggledy assortment of highfalutin science, lowfalutin sciences, tests" and more, Marx explores memory slippage, mindfulness, the Cherokee language and brain scans. If you regularly arrive in rooms with no memory of what you were looking for, this one is for you. Barbara Kiser 